\title{
ANOREXIA AND THE REFUSAL OF MEDICAL TREATMENT
}

\author{
Jo Oliver
}

The Bill of Rights Act 1990 gives everyone the right to refuse medical treatment. In Re CMC, the right of an anorexic patient to refuse treatment was overridden by the Family Court. Anorexia nervosa is recognised as a mental illness which predominantly affects women. This paper considers the philosophical and legal basis for that decision. The writer also touches on the wider ethical and social issues raised by the decision.

\section{INTRODUCTION}

In the case of $\operatorname{Re} C M C^{1}$ Judge MacCormick made an order that nasogastric feeding be administered to a 33 year old anorexic patient (CMC) against her wishes. This was the first reported judgment in New Zealand on this subject. The application was made by CMC's husband, under section 10(1)(f) of the Protection of Personal and Property Rights Act 1988. The judgment also mentions their two children, aged eleven and seven. It was an application of last resort, since CMC's 20-year illness had become severe and her weight was so low that her life was in danger. As well as the immediate danger to her life, CMC had little chance of survival in the long term unless she gained weight.

The decision raises some important issues. Anorexia nervosa has become recognised as a mental illness which predominantly affects women. The origin of the disease partly lies in social pressures to conform to an ideal body shape. Although she had anorexia, CMC had a right to refuse medical treatment which had to be overridden by the court. Her doctors had an interest in giving her treatment to save her life. Her husband and children had a more personal interest in keeping her alive and helping her to recover. The State also had an interest in preserving CMC's life. Re CMC illustrates the conflict of these rights and interests and one possible resolution of them in the circumstances.

* This paper was submitted as part of the LLB(Hons) programme.

1 [1995] NZFLR 341. 
This paper will begin in Part I by outlining the reasoning of Judge MacCormick. Part II goes on to consider the issue of competence to refuse treatment. Part III begins to explore some of the rights and interests mentioned above. In Part IV the writer concludes that the decision was the correct one in the circumstances.

\section{THE DECISION OF JUDGE MACCORMICK}

The judgment begins with the basic position on the refusal of medical treatment. At common law, no treatment may be administered without the patient's consent: ${ }^{2}$

Every human being of adult years and sound mind has a right to determine what shall be done with his own body, and a surgeon who performs an operation without his patient's consent commits an assault, for which he is liable in damages.

In addition, section 11 of the New Zealand Bill of Rights Act 1990 states that "[e]veryone has the right to refuse to undergo medical treatment."

Section 10(1)(f) of the Protection of Personal and Property Rights Act (the "PPPR Act") is a statutory exception to the right to refuse medical treatment. Under this section, the Family Court has jurisdiction to make an order that a person be provided with medical treatment of the kind specified in the order. This order overrides any refusal of consent on the part of the patient.

According to the statute, there are two stages to the decision to grant an order for medical treatment. ${ }^{3}$ The first stage is to establish jurisdiction to make an order. The second stage is an exercise of the court's discretion as to whether to make the order.

The court has jurisdiction to make an order under section 6 when the person :

(a) Lacks, wholly or partly, the capacity to understand the nature, and to foresee the consequences, of decisions in respect of matters relating to his or her personal care and welfare; or

(b) Has the capacity to understand the nature, and to foresee the consequences of decisions in respect of matters relating to his or her personal care and welfare, but wholly lacks the capacity to communicate decisions in respect of such matters.

Section 5 states that the person is to be presumed competent until proven otherwise. Further, section 6(3) states that :

(3) The fact that the person in respect of whom the application is made for the exercise of the Court's jurisdiction has made or is intending to make any decision that a person

2 Schloendorff $v$ Society of New York Hospital 105 NE 92, 93 (1914).

3 Protection of Personal and Property Rights Act, s 9. 
exercising ordinary prudence would not have made or would not make given the same circumstances is not in itself sufficient ground for the exercise of that jurisdiction by the court.

These provisions reflect the principle that unless a person is proven to lack capacity, that person should be able to make their own treatment decisions, even if those decisions seem unreasonable.

In $C M C$, Judge MacCormick found that CMC lacked capacity in three respects: her understanding of relevant information, her appreciation of the situation and its consequences and her ability to follow a logical sequence of thought in order to reach a decision. ${ }^{4}$ She did not "understand or appreciate" that her illness was life-threatening. She "could not perceive" that nasogastric feeding was virtually necessary in order for her to survive. Her thought process was not logical in that she wanted to survive, but could not see that she would have to gain weight in order to do so. She tended to blame others for her situation. All this was due to her anorexia nervosa: ${ }^{5}$

...she was doing it as a feature of her illness, which is in essence an illness of mental disorder and lack of rational perception in this area. It is something which I merely note without any connotation of blame. If she were in her right mind, she would perceive that in fact she has very considerable control over the situation and that from a rational perspective she has been enormously manipulative. But it is not to be looked at as if she were able to perceive the situation rationally - for I am satisfied that she has not been able to. The disorder is compulsive for her and, in Dr Clarkson's [her psychiatrist's] evidence, overrides absolutely everything else such as her love for her children, her wish to be fit and well and healthy and independent again, indeed, her expressed wish to recover.

Once it has been established that the Court has jurisdiction, there is still a discretion as to whether to make the order. ${ }^{6}$ According to section 6 of the Act, in exercising this discretion the primary objectives of the Court are :

(a) To make the least restrictive intervention possible in the life of the person in respect of whom the application is made, having regard to the degree of that person's incapacity;

(b) To enable or encourage that person to exercise and develop such capacity as he or she has to the greatest extent possible.

4 Above n 1, 344.

5 Above n 1, 345.

6 Protection of Personal and Property Rights Act, s 9(2). 
The High Court case of In the Matter of $A,{ }^{7}$ decided after $R e C M C$, held that the patient's "welfare and best interests" is another objective which the court has regard to in exercising its discretion.

In the context of objectives, forced nasogastric feeding was not seen as an ultimate long term cure for $\mathrm{CMC}^{8}$ Rather it was a temporary measure to help CMC overcome her illness. CMC's psychiatrist stated that: ${ }^{9}$

It is my opinion that CMC's fear of weight gain is so overwhelming that despite her best intentions she [is] quite unable to eat enough to gain further weight. It is possible that if she can be re-fed to a more healthy weight by nasogastric feeding that she will be able to deal with her fears of weight gain and that her ability to think more rationally about her situation will improve with better nutrition. It is also my opinion that without nasogastric feeding we will make no further progress regarding her weight.

In finally granting the order, Judge MacCormick stated: ${ }^{10}$

Had CMC not expressed a wish to live, to recover fully and to lead a future life with her family and in particular her children, then in exercising the ultimate discretion it may perhaps have been appropriate to decline to make the order. But having regard to her stated wishes (other than those relating to treatment), I was satisfied that the proposed treatment was the least restrictive supplementary treatment that was available and that it was a form of treatment which hopefully might enable CMC to ultimately exercise and develop her own capacity to overcome her illness. In that regard Dr Clarkson remained optimistic that she still had a good chance of doing so if the initial physical problem could be addressed. It was in these circumstances that the Court accepted responsibility for making the order sought.

\section{COMPETENCE TO REFUSE MEDICAL TREATMENT}

\section{A Justification for Providing Medical Treatment to Incompetent Patient}

At common law, the right to refuse medical treatment is based on the inviolability of the body. ${ }^{11}$ Philosophically, the right is based on the principle of autonomy or selfdetermination. The underlying idea is that a decision which is the result of an individual's free choice is a valuable decision regardless of its actual content. So if an individual freely

7 [1996] NZFLR 359.

8 Above $\mathrm{n} 1,343$

9 Above n 1, 346.

10 Above n 1, 346

11 In re F (Mental Patient : Sterilisation) [1989] 2 WLR 1063, 1082. 
makes a choice which we consider to be a bad one, that choice should nevertheless be respected.

As well as the value of personal autonomy, there is the principle of individual wellbeing. In the medical context, this is the idea that any action we take should promote the patient's physical and mental health. The two principles are linked in that it will usually promote the patient's well-being to allow her ${ }^{12}$ to make her own decisions with respect to medical treatment. This is for two reasons. The first is that, generally, the patient is the best judge of what is in her own interests. Her best interests may be personal to her in that they depend on her own values and goals. Secondly, it promotes the patient's emotional wellbeing to allow her to make her own decisions about personal matters in her life.

In some situations, the two values of respect for personal autonomy and promotion of well-being come into conflict. This happens when the patient makes a choice that we think is not in her best interests, or will not promote her well-being. The issue then becomes the relative weight to be given to the two conflicting principles. ${ }^{13}$

Recent developments in the law tend to give more weight, or a presumptive weight, to the patient's autonomy. The PPPR Act is an example of legislation which focuses on patient autonomy instead of paternalistic judgments as to what is right for the patient. Under the Act, a patient is presumed competent until proven otherwise, and no intervention can be ordered unless there is a finding of incompetence.

So when are we justified in overriding a patient's decision? Following the principle of respect for autonomy, we may be justified in overriding a patient's refusal of treatment if the patient has not truly made a free choice. Patients who lack decision-making capacity or competence are not acting with true autonomy when they make decisions. ${ }^{14}$ Such decisions are not inherently valuable. Where a patient lacks competence, we are justified in giving greater weight to the promotion of her well-being than to her personal autonomy. In such situations we need to protect the patient from her own harmful decisions.

Even if intervention is justified, personal autonomy should still be respected. In order to do this, any intervention should be the minimum necessary to promote the patient's

12 The patient is referred to in the feminine gender throughout this paper, since anorexia patients are predominantly female.

13 This analysis of the principle of autonomy and the principle of well-being is taken from $\mathrm{AE}$ Buchanan and DW Brock Deciding for Others - The Ethics of Surrogate Decision Making (Cambridge University Press, Cambridge, 1989) 29-41.

14 I Kennedy and A Grubb Medical Law - Texts and Materials (2 ed) (Butterworths, London, 1989) 202. 
interests. ${ }^{15}$ Excessive intervention would go beyond the limits of the justification. This idea is reflected in the PPPR Act in section 8(a), which states that any intervention should be the least restrictive possible having regard to the degree of the patient's incapacity.

The type of treatment should also reflect the principle of autonomy. For example, the treatment given could be one which it is thought the patient would choose if competent. This means that the patient's personal values and goals, if known, can be promoted. With temporarily incompetent patients, the goal of intervention could be to promote the patient's autonomy in the long term. ${ }^{16}$ The medical treatment is then justified as a means of bringing the patient to a state of true autonomy. This is reflected in the PPPR Act in section 8(b), which states that an objective of treatment is to help the patient to develop her future capacity to make decisions.

\section{B Criteria for Competence}

Since the justification for imposing treatment without the patient's consent is based on incompetence, the determination of competence is a central issue. One writer has stated that the question of what the criteria for competence are has generally been ignored by lawyers. ${ }^{17}$ Until recently, no English judgment had directly addressed the issue. ${ }^{18}$ Courts have tended to rely on psychiatric evidence. This is a mistake since an assessment of competence involves social and legal factors as well as medical ones. ${ }^{19}$

Under the PPPR Act, there is some statutory guidance as to what constitutes incompetence. The section 6 test is that the patient "[l]acks, wholly or partly, the capacity to understand the nature, and to foresee the consequences, of decisions in respect of matters relating to his or her personal care and welfare".

The incapacity is stated to be with respect to decisions relating to personal care and welfare. In CMC, and similar cases, the decisions concerned are decisions with respect to medical treatment. So a person is not found competent or incompetent in general, but only incompetent with respect to certain decisions. ${ }^{20}$ For example, an intellectually handicapped person may be perfectly competent to decide what to eat for lunch, and that decision ought to

15 Above n 14, 293.

16 Above n 14, 204.

17 M Brazier "Competence, Consent and Proxy Consents" in M Brazier and M Lobjoit (eds) Protecting the Vulnerable - Autonomy and Consent in Health Care (Routledge, London, 1991) 48.

18 The recent case of $\operatorname{Re} C$ (adult : refusal of medical treatment) [1994] 1 All ER 819 does address the issue.

19 Above n 14, 196. 
be respected. However, he may be incompetent to enter into a mortgage transaction because he has no understanding of the concept of legal obligation or of the long term future. ${ }^{21}$

What does it mean to lack the capacity to "understand the nature and foresee the consequences" of a decision? The statutory words follow the common law test used by English courts, that a patient must "understand the nature, purpose and effects" of treatment. ${ }^{22}$ So in interpreting the PPPR Act test, general common law criteria for competence are relevant.

Some very basic requirements for competence are an ability to focus attention on what is said, an ability to listen and an adequate memory. ${ }^{23}$ There is no doubt that CMC met these very basic criteria. Another basic criterion is the ability to communicate decisions. Under the PPPR Act, if a person wholly lacks this ability, the patient is deemed incompetent for the purposes of section 6(b). Again, there was no question that CMC lacked any ability to communicate.

It is necessary to consider some more sophisticated criteria for competence. In Re CMC, Judge MacCormick made use of three factors ${ }^{24}$ which were identified in the earlier case of In the matter of FT: ${ }^{25}$

(1) understanding of relevant information

(2) appreciation of the situation and its consequences

(3) ability to follow a logical sequence of thought in order to reach a decision.

In $\operatorname{Re} C,{ }^{26}$ a decision in the Family Division in England, the following three stages to a decision about medical treatment were identified and applied: ${ }^{27}$

(1) to take in and retain treatment information

(2) to believe it

(3) to weigh the information, balancing risks and needs.

21 J Dawson The Implementation of the Protection of Personal and Property Rights Act 1988 : the Report of a Pilot Study in Dunedin (Bioethics Research Centre of the University of Otago, Dunedin, 1994) 63.

22 Chatterton $v$ Gerson [1981] QB 432; Re C, above $n 18$.

23 B James "The Disabled and the Law" (1990) 2 FLB 62.

24 Above n 1, 344.

25 Unreported, 11 January 1995, District Court, Auckland Registry, PPPR 68/94.

26 Above $\mathrm{n} 18$.

27 Above n 18, 822, 824. 
This three stage test has been accepted as useful by academics, ${ }^{28}$ and is similar to the approach recommended by the English Law Commission. ${ }^{29}$ The three stages correspond roughly to the three factors applied in $\operatorname{Re} C M C$. Stage (1) is a basic test of understanding or cognitive skills. Stage (2) tests whether the patient appreciates the significance of the information, or its reality. Stage (3) tests whether the patient can piece the information together in order to reach a decision. Some writers ${ }^{30}$ include a fourth criterion - a set of values or conception of what is good. This can be subsumed under (3). The process of weighing the information involves evaluating particular outcomes as good or bad according to the patient's value system.

\section{Reasonableness of the Decision to Refuse Treatment}

It is not part of the criteria that the decision actually reached be reasonable. There is a temptation, when a patient makes a decision that seems unreasonable, to think that the patient must be incompetent. This temptation should be resisted, because it fails to respect the patient's autonomy and imposes the judgment of the doctor, or society as to what is reasonable. In effect, it looks at the outcome of the patient's decision-making and finds it defective. This means that those who have different or unusual value systems can be found incompetent.

The criteria above focus instead on the process of decision-making. If the process is defective, then intervention is justified. The PPPR Act recognises this problem, and section $6(3)$ states that a patient cannot be declared incompetent merely because the decision is not one that a person of "ordinary prudence" would make.

This right to make unreasonable decisions was affirmed in the English Court of Appeal in the case of $R e T .{ }^{31}$ In that case, the patient refused consent to a blood transfusion because of her Jehovah's Witness faith. The Court made it clear that "an adult person of sound mind" has an absolute right to refuse medical treatment, even if that refusal is unreasonable in the circumstances, and even if it will probably lead to the patient's death. ${ }^{32}$ This is an example of the value of autonomy being placed more highly then the promotion of the patient's

28 K Stern "Competence to Refuse Life-Sustaining Medical Treatment" [1994] 1 FLR 31. The test was approved in Home Secretary $v$ Robb [1995] 1 All ER 677, 681. A similar three stage test was approved by Kennedy and Grubb, above n 14, 198, 215 and Buchanan and Brock, above $n$ 13, 2325.

Above n 18, 824.

30 Buchanan and Brock, above n 13, 23-25; President's Commission in Kennedy \& Grubb, above n 14, 198.

31 [1992] 3 WLR 782.

32 Above n 31, 786-787. 
physical well-being. It may be thought that her emotional or spiritual well-being would suffer more if treatment was imposed.

It is important to see that a person who refuses medical treatment on religious grounds can be competent, although her decision seems unreasonable. A Jehovah's Witness patient who refuses a blood transfusion typically does so because of the belief that having another's blood in one's body is like taking another's soul. The result of a blood transfusion is that the person will not achieve eternal life. The Jehovah's Witness patient may believe that it is better to die from refusing a blood transfusion than to accept one and live contrary to the faith. This seems unreasonable to many of us because we do not share these beliefs.

Consider a Jehovah's Witness patient against the three criteria for competence listed above. The Jehovah's Witness understands that the blood transfusion is to replace lost blood, and believes that she may die without the transfusion. She weighs the information, and decides that it is better to refuse the transfusion. So although the criteria require her to balance risks and needs, we cannot tell her what weight to place on the various factors. She cannot be held incompetent for failing to place the "correct" weight on the risk of dying. Further, she is following a logical sequence of thought. If she accepts the transfusion, she will suffer eternal damnation. In these circumstances, it is logical for her to refuse the transfusion. She has freely made the choice to have this value system, and she is now freely choosing to follow it.

Despite this pronouncement of the right to make unreasonable decisions, the fact remains that in practice, many decisions are judged according to whether they are reasonable. According to some writers, competence tends to be judged on the risk-benefit ratio of the particular treatment. ${ }^{33}$ So if a particular treatment has little or no risk, and would benefit the patient by saving their life, a patient who refuses this treatment would tend to be held incompetent. In effect, this means that the more the patient's physical well-being is in danger, the less weight is given to personal autonomy.

This argument is supported by case law. Courts are extremely reluctant to allow someone to die when a low-risk treatment is available. ${ }^{34}$ So in $\operatorname{Re} T$, although the patient was generally competent, the court found that at the time of making the decision, she was physically and emotionally weak and so prone to the influence of her mother. ${ }^{35}$ This justified setting aside her decision.

33 Roth, Meisel and Lidz in Kennedy \& Grubb, above n 14, 195; M Nicholls "Consent to Medical Treatment" [1993] Family Law 30, 32.

34 K Stern, above $\mathrm{n} 28,542$.

35 Above n 31, 794-795. 
These factors should be borne in mind when considering $R e C M C$. CMC refused nasogastric feeding. Although the treatment was not guaranteed to save her life, medical evidence indicated she would die without it. The treatment itself was not risky. Most people would consider her decision an unreasonable one. The question remains whether the case is an example of society imposing its judgment as to what is reasonable and in CMC's best interests. The key to this lies in the link between CMC's mental illness and her refusal of treatment.

\section{CMC, Anorexia Nervosa and Competence}

CMC had suffered from anorexia nervosa for 20 years, and her illness had been severe for seven years. Anorexia nervosa is a recognised mental illness. However, a diagnosis of anorexia is not enough to prove that CMC is incompetent for the purposes of the PPPR Act. What must be proven is that CMC lacked capacity according to the criteria set out above. It is therefore necessary to show how CMC's mental illness affected her capacity.

The link between a person's mental illness and competence to make decisions was considered in $\operatorname{Re} C .^{36} \mathrm{C}$ was a 68 year old patient suffering from paranoid schizophrenia. He developed gangrene in his foot, and his condition worsened to the extent that he was likely to die imminently unless his foot was amputated. C refused consent to the amputation, although he consented to other medical treatment.

The issue was C's competence to consent. C had some strange beliefs, including the belief that he was a world famous doctor and the belief that he was being persecuted. Thorpe $\mathrm{J}$ found that C's refusal of treatment was not a result of his mental illness. C's refusal was simply a result of his ordinary value judgment that it would be better to die with two feet than to live with one. With respect to the decision not to amputate, $C$ passed all three stages of the competence test.

So how does anorexia affect a person's competence? Anorexia nervosa is an eating disorder, so primarily it affects a person's eating habits. ${ }^{37}$ Anorexics are generally obsessed with food and dieting, and afraid of gaining weight. Their fear of weight gain causes them to become manipulative and deceitful in order to avoid eating without arousing the suspicion of others. Anorexics behave compulsively. Their urge to diet is beyond their control.

Another feature of anorexia relates to control. Many anorexics have grown up feeling that they were not in control of important aspects of their lives. The development of an

36 Above n 18.

37 This summary of anorexia is taken from an interview with Jane Scott, psychologist at the Child and Family Clinic, Lower Hutt. 
anorexic's illness can often be traced to a subconscious desire to control her environment. The most obvious manifestation of this is the obsessive need to control her food intake.

This desire to be in control means that anorexics want to deal with the illness by themselves. They see medical intervention as a threat to their control. Forced nasogastric feeding, then, is an extreme form of loss of control for an anorexic patient. Further, anorexics' fear of weight gain means that they routinely refuse artificial feeding. So special considerations apply to anorexia when considering the issue of competence to refuse treatment.

The fact that anorexia affects mainly women suggests that other special considerations may apply. The psychological cause of anorexia is often low self esteem, sometimes caused by society's perceptions of how a woman should look. Therefore it is important to distinguish behaviours stemming from low self esteem from the mental disorder that is anorexia nervosa.

\section{E Anorexia Nervosa and Criteria for Competence}

The three criteria for competence are

(1) ability to understand information

(2) ability to appreciate situation and consequences / believe the information

(3) ability to follow logical sequence of thought in order to reach a decision.

In this context, the decision is to refuse nasogastric feeding for anorexia, and the information is the medical information relating to CMC's prognosis.

In $\operatorname{Re} C M C$, Judge MacCormick found that CMC failed all three stages of the test, due to her anorexia. ${ }^{38}$ In his words, she did not "understand or appreciate" the threat to her life, because she could not "bring herself to understand it". She also did not have the facility to consider the matter logically, since although she wanted to live, she "could not see" what was necessary in order for this to be achieved. She could not "perceive the situation rationally".

It is submitted, with respect, that CMC and anorexic patients generally, do not fail the test at step (1) "understanding", but at step (2) or (3). ${ }^{39}$ It is possible to distinguish two types of defect in a patient's decision-making. ${ }^{40}$ One is misunderstanding about the nature and likelihood of the outcome of treatment. This is generally associated with either a lack

38 Above n 1, 344-345.

39 Jane Scott confirmed this. See also K Stern, above n 28, 544.

40 Above n 13, 56. 
of information, or a limit in cognitive understanding. The other possible defect is where the patient's choice fails to reflect her underlying aims and values.

On this analysis, step (1) is a fairly basic test. ${ }^{41}$ It is submitted that CMC passed step (1) of the test. She understood what nasogastric feeding was, and why it was being recommended to her. She understood that its purpose was to help her increase her weight. She understood the concepts involved.

At stage (2), it is more difficult to say whether CMC "understood" that her illness was life-threatening. Judge MacCormick found that she did not believe that she was close to death, or that refusing treatment would threaten her life even further. The issue that arises is whether CMC knew deep down that her life was in danger, and refused treatment anyway because of her overriding fear of weight gain, or whether she genuinely did not believe that she would die because her illness caused her to distort the information. The literature on anorexia ${ }^{42}$ is not decisive on this point. It appears to depend on the individual case as to whether the anorexic patient believes or accepts that her illness is lifethreatening. Generally, she will deny this, at least outwardly. So CMC probably did fail step (2) of the competence test.

At stage (3), CMC was unable to think logically because her illness was compulsive. She wanted to live, but compulsively refused food and treatment. This distinguishes her from the Jehovah's Witness patient who freely chooses to value her faith above her life. It also distinguishes her from $\mathrm{C}$, who would rather die than have an amputation. CMC's decision to refuse food was not a free decision to value being thin over being alive. Her mental illness meant that she had a compulsive fear of gaining weight, and of losing control, which overrode everything else. Her refusal was not the result of her ordinary beliefs, it was the result of her mental illness.

It is useful to compare this analysis of anorexia and competence with the discussion in two recent English cases. The first is $R e W{ }^{43}$ This case, in the English Court of Appeal, concerned the right of a 16 year old anorexic patient to refuse treatment. The issue in the case was whether, as a 16 year old minor, $W$ had an absolute right to refuse medical treatment. The result was that she did not have this right. If she refused medical treatment, consent could be obtained from a parent or from the court.

41 M Brazier, above n 17, 36.

42 AH Crisp Anorexia Nervosa - Let Me Be (Academic Press, London, 1980) 149; IL Mintz "Psychoanalytic Description : The Clinical Picture of Anorexia Nervosa and Bulimia" in CP Wilson, IL Mintz, CC Hogan (eds) Fear of Being Fat (Jason Aranson Inc, London, 1987) 85; MS Palazzoli Self Starvation (Jason Aranson, London, 1986) 82. 
W's actual competence to consent, and how her anorexia affected this, was not an issue on appeal. However, some of the obiter comments are useful. At first instance, the judge had found that $\mathrm{W}$ was competent to make treatment decisions. However, two of the judges on appeal expressed the view that she was in fact incompetent due to her anorexia. Counsel conceded during the case that it is a feature of anorexia that it "is capable of destroying the ability to make an informed choice". Lord Donaldson stated that it creates a compulsion to refuse effective treatment, and a firm wish not to be cured unless and until the sufferer wishes to cure herself. ${ }^{44}$ Balcombe $\mathrm{LJ}$ also referred to the effect of anorexia on the ability to make an informed choice. ${ }^{45}$ The judges' comments indicate that they thought $\mathrm{W}$ failed stage three of the competence test. They indicate elsewhere ${ }^{46}$ that $\mathrm{W}$ is intelligent and quite capable of understanding the situation. Lord Donaldson also noted that it did not seem to have occurred to $\mathrm{W}$ that she might "leave it too late", ie that she might die if she refused treatment. This indicates that she may have failed the test at the second stage also.

Another recent English case is South West Hertfordshire Health Authority $v$ KB. ${ }^{47}$ The anorexic patient, $\mathrm{KB}$, did not appreciate the situation she was in. She saw "the prospect of death as a long-term or theoretical prospect".48 Ewbank J distinguished her situation from that of $\mathrm{C}$, the paranoid schizophrenic. ${ }^{49}$ Unlike C, K's refusal was a result of her mental illness.

\section{F Mental Health (Compulsory Assessment and Treatment) Act 1992}

The PPPR Act provides a framework in which to judge a patient's competence to consent, and to impose treatment if the patient is found to be incompetent. Another framework for this is the Mental Health (Compulsory Assessment and Treatment) Act 1992 (referred to throughout this paper as the "MH Act").

In $\operatorname{Re} C M C$, Judge MacCormick stated that :

Anorexia nervosa is, of course, a disorder of the mind and patients with the disease in a sufficient state of severity have been considered to be mentally disordered in terms of the Mental Health (Compulsory Assessment and Treatment) Act 1992. Some have been held to require a compulsory treatment order under that Act.

44 Above $\mathrm{n} 43,630$.

45 Above $\mathrm{n} 43,640$.

46 Above n 43, 637.

47 [1994] 2 FCR 1051.

48 Above $\mathrm{n} 47,1052$.

49 Above n 47, 1054. 
The MH Act could have been invoked in $R e C M C$. The Act has been used, in rare cases, to force-feed anorexic patients. Re CMC appears to be the first case where the PPPR Act was used for this purpose. This raises the question of why the PPPR Act was used in CMC's case.

The key definition in the MH Act is that of "mental disorder".50

"Mental disorder", in relation to any person, means an abnormal state of mind (whether of a continuous or an intermittent nature), characterised by delusions, or by disorders of mood or perception or volition or cognition, of such a degree that it - (a) poses a serious danger to the health or safety of that person or of others; or (b) seriously diminishes the capacity of that person to take care of himself or herself; - and "mentally disordered", in relation to any such person, has a corresponding meaning:

The definition has two limbs. The first limb requires an "abnormal state of mind", characterised by certain phenomena. The second limb specifies outcomes of that state of mind. So the abnormal state of mind itself is not enough, the outcomes must be present before intervention is justified.

In terms of the first limb, anorexia gives rise to an abnormal state of mind, characterised by "disorders of ... volition". A disorder of volition is something which affects a person's choice and / or control of their behaviour. ${ }^{51}$ So anorexia affects a person's ability to choose to eat properly, and her ability to control her eating habits.

In terms of the second limb, anorexic patients whose illness is sufficiently severe pose a serious danger to their own health, and have a seriously diminished capacity to take care of themselves. This explains Judge MacCormick's comment that only patients with anorexia "in a sufficient state of severity" are "mentally disordered" within the Act.

Under the MH Act, there are two basic stages to the process of compulsory assessment and treatment. The first is a period of initial assessment and treatment which can last as long as a month. ${ }^{52}$ This period begins when a medical practitioner, usually a psychiatrist, decides that there are reasonable grounds for believing that a person is "mentally

50 Mental Health (Compulsory Assessment and Treatment) Act 1992, s 2.

51 J Anderson "Psychiatric Decision-making in the Compulsory Assessment Process" in The Mental Health (Compulsory Assessment and Treatment) Act 1992 (NZLS, Wellington, 1992) 56.

52 Mental Health (Compulsory Assessment and Treatment) Act 1992, s 10-14. 
disordered". 53 During this period, the patient is "required to accept such treatment for mental disorder" as the psychiatrist directs. ${ }^{54}$

The second stage is reached when a court grants an application for a compulsory treatment order (CTO). ${ }^{55}$ Before granting the order, the court must be satisfied that the person is mentally disordered. During the first month of a CTO, the patient is again required to accept the treatment for mental disorder which the psychiatrist recommends. ${ }^{56}$

Once one month has passed since the granting of the CTO, treatment cannot be administered without the patient's consent, unless a second psychiatrist approves the treatment as being in the patient's interests. ${ }^{57}$ This requirement of a second opinion can be overridden if treatment is necessary to save the patient's life or to prevent serious damage to the health of the patient. ${ }^{58}$

\section{G The PPPR Act and the Mental Health Legislation}

Given that the Mental Health Act framework is available, why use the PPPR Act in this situation? In Re CMC, Judge MacCormick stated that: ${ }^{.9}$

Mr C [CMC's husband] was advised that an application under the Protection of Personal and Property Rights Act was in fact a less intrusive application than one under the Mental Health Act....

Although an order under the Protection of Personal and Property Rights Act is probably not as far reaching in its effect as a compulsory treatment order under the Mental Health Act, it is nevertheless, in my view, just as difficult to obtain.

There is a stigma associated with becoming a compulsory patient under the Mental Health Act. CMC wanted to avoid the stigma of "committal proceedings", and this appears to be a major reason why the application was made under the PPPR Act. ${ }^{60}$ This stigma was also mentioned by Lord Donaldson in $\operatorname{Re} W$, the English case of the 16 year old anorexic.

53 Above n 52, s 10(1)(b).

54 Above n 52, s 58.

55 Above n 52, ss 18-27.

56 Above n 52, s 59(1).

57 Above n 52, s 59(2).

58 Above n 52, s 62.

59 Above n 1, 343.

60 Above n 1, 343. 
He stated that the English Mental Health Act probably did not apply to W, but that even if it did, it would be better to secure treatment on some other basis: ${ }^{61}$

Although mental illness should not be regarded as any different from physical illness, it is not always so viewed by the uninformed and the fact that in later life it might become known that a minor has been treated under the [Mental Health] Acts might rebound to his or her disadvantage.

Apart from the general stigma of being a mental patient, it is clear that the MH Act authorises far more intervention than the PPPR Act. Judge MacCormick's observation that a PPPR Act application is less intrusive ${ }^{62}$ than a $\mathrm{MH}$ Act one is correct in several respects.

First, under the MH Act, treatment may be imposed without the patient's consent on the approval of one psychiatrist. This can continue for a month before an application is made to court. The approval of a second psychiatrist is not required until after the first month of the CTO. No second opinion is required where the patient's life is in danger, as it would be where nasogastric feeding is imposed for anorexia. In contrast, under the PPPR Act a court order is required before treatment can go ahead. This means that the patient's case is subject to scrutiny by an independent body.

There are situations where it is particularly desirable to obtain a court order before proceeding with treatment. An example is the New Zealand case of $\operatorname{Re} W{ }^{63} \mathrm{~W}$ was a 74 year old patient who was already subject to a CTO under the $\mathrm{MH}$ Act, for severe depression. He was not eating, and medical evidence indicated that if he did not receive treatment urgently, he would die within a few days. The proposed treatment was electroconvulsive therapy (ECT). This was accepted to be the only available option, but it carried substantial risk to $\mathrm{W}$. W was incapable of giving consent, so the treatment could be given under the MH Act only if a second psychiatrist recommended it as in W's interests. Because of the high risk involved in treatment, it was not possible or desirable for a psychiatrist to do this. W's own psychiatrist had applied to the court because she did not want to be responsible if W's death resulted from treatment. This was a case where an order by an independent court was appropriate. In granting the order under the PPPR Act, Judge Boshier stated that it was a "good illustration [of] the way in which the two Acts are capable of intertwining to provide clear guidelines in cases where there is demonstrable

61 Above n 43, 639.

62 In the matter of IMT [1994] NZFLR 612, alternative applications were made under the PPPR Act and The Mental Health Act. Judge Green granted the PPPR Act application because it was "less intrusive" to the patient's rights.

63 (1994) 12 FRNZ 573. 
risk". ${ }^{64}$ It is submitted with respect that the relation between the two Acts is far from "clear".

There may be situations where a court order is not appropriate. The obvious one is a case of emergency, where the delay of court proceedings may present a problem. However, in emergency situations courts are willing to speed up the process. CMC itself was an urgently scheduled hearing. Another consideration with court proceedings is the stress which may be caused to the patient by litigation. ${ }^{65}$

As well as requiring a court order, the PPPR Act is less intrusive in other substantive respects. Each order for medical treatment under the PPPR Act requires a finding that the patient is incompetent to make that particular decision. Only then does the patient lose her right to refuse treatment. In contrast, a patient under the MH Act loses her right to refuse when she is declared to be "mentally disordered" by a psychiatrist and later by the court. There is no assessment of her competence to make individual decisions. In this way, it may be more difficult to obtain an order under the PPPR Act, not "just as difficult" as Judge MacCormick states.

The PPPR Act is also less intrusive in the types of treatment which it allows. The treatment is that specified in the court order, which must be the least restrictive possible, and designed to encourage the patient to develop her future capacity. Under the MH Act, a psychiatrist is authorised to give any medical treatment for mental disorder. This is for the discretion of the psychiatrist. There are no principles in the $\mathrm{MH}$ Act to guide the psychiatrist's choice of treatment. This is what Judge MacCormick referred to when he said that an order under the PPPR Act is not as "far reaching" as one under the MH Act.

Although the MH Act authorises any treatment for mental disorder, it authorises only medical treatment for mental disorder. So when a patient is subject to compulsory treatment under the MH Act, it may still be necessary to obtain an order under the PPPR Act for medical treatment for a physical problem. This occurred in $\operatorname{Re} W,{ }^{66}$ where an unstable mentally disordered patient was refusing the medical treatment necessary for the safe delivery of her baby.

\section{H Nasogastric Feeding as a Treatment for Anorexia Neroosa}

Since the MH Act has been used in New Zealand for nasogastric feeding of anorexic patients, it must be assumed that those involved have seen no problem with this treatment

64 Above $n$ 63, 575.

65 M Mulholland "Re W : Autonomy, Consent and the Anorexic Teenager" (1993) 9 Professional Negligence 21, 24.

66 (1993) 11 FRNZ 108. 
fitting the description of "medical treatment for mental disorder". This may be because the position is now settled in England.

There was initially doubt in England as to whether this treatment was medical treatment for mental disorder within the English Mental Health Act. ${ }^{67}$ The first difficulty was in regarding nasogastric feeding as "medical treatment" at all, since all it does is provide the patient with artificial nutrition. This was settled in 1993 when the House of Lords held that nasogastric feeding is medical treatment. ${ }^{68}$

The more difficult issue is whether nasogastric feeding can be described as treatment for a mental disorder. If a mental disorder causes someone to refuse food, then nasogastric feeding treats the physical symptoms, but does not directly treat the underlying mental disorder. ${ }^{69}$ Directly treating the mental disorder generally involves psychotherapy.

This issue was addressed in England in the Family Division in South West Hertfordshire Health Authority $v K B .{ }^{70}$ In that case, Ewbank J accepted counsel's argument that: ${ }^{71}$

anorexia nervosa...is an eating disorder and relieving the symptoms is just as much a part of treatment as relieving the underlying cause. The symptoms are exacerbated by the patient's refusal to eat and drink, the mental disorder becomes progressively more and more difficult to treat and so the treatment by naso-gastric tube is an integral part of the treatment of the mental disorder itself....the treatment is necessary in order to make psychiatric treatment of the underlying cause possible at all.

This reasoning was endorsed by Hoffmann $\mathrm{LJ}$ in the English Court of Appeal in $B v$ Croydon Health Authority. ${ }^{72}$ In the Croydon case, nasogastric feeding was endorsed as treatment for a psychopathic disorder. This shows that the reasoning extends beyond eating disorders.

So whether nasogastric feeding of an anorexic is medical treatment for mental disorder depends on the purpose of nasogastric feeding. If there was no proposed treatment for the anorexia, and the feeding was simply to keep the patient alive, then strictly it would not be authorised by the UK Mental Health Act. ${ }^{73}$ There are no relevant differences in the New

67 P Fennell "Force Feeding and the Mental Health Act 1983" (1995) 145 New Law Journal 319.

Airedale NHS Trust $v$ Bland [1993] AC 789.

This problem was considered in B $v$ Croydon Health Authority [1995] 1 All ER 683, 687.

Above $\mathbf{n} 47$.

Above $n$ 47, 1053.

Above $\mathrm{n} 69$. 
Zealand MH Act which indicate that a different approach should be taken in this country. The feeding must be part of, or a prerequisite to, treatment for anorexia.

Nasogastric feeding is imposed only where the patient's life is in danger. A psychologist ${ }^{74}$ I spoke to characterised the treatment as one designed primarily to save the patient's life. This is a prerequisite for treatment for anorexia in the loose sense that treatment is not possible if the patient is dead.

In $\operatorname{Re} C M C$, Judge MacCormick said that the purpose of treatment was to get CMC to a physical condition where she could think rationally about her situation and "address issues necessary for her to recover". ${ }^{75}$ Under the PPPR Act, the court can order any medical treatment, not just treatment "for mental disorder". However, the Judge's statement shows that he characterised the feeding as a prerequisite to psychiatric treatment for anorexia.

It is submitted, with respect, that the basis on which the English decisions declared nasogastric feeding for anorexia to be "medical treatment for mental disorder" is questionable. The issue did not arise in $\operatorname{Re} C M C$, but it is likely that a New Zealand court would follow the reasoning of the English cases. It is interesting to note that in England, there is no alternative statutory procedure such as the PPPR Act in New Zealand.

There are some remaining issues relating to nasogastric feeding as a treatment for anorexia. Writers on anorexia are agreed that nasogastric feeding should be imposed only in cases where the patient's life is at risk. ${ }^{76}$ The problem with imposed feeding is that it tends to "reconfirm anorexics' earlier experiences of life" 77 in that it deprives them of any control over their situation. This can result in the patient becoming even more uncooperative. The psychological damage caused by imposed feeding can create further deterioration in the patient's mental condition. The weight gain caused by imposed feeding may cause her to panic and attempt to lose even more weight once the feeding is over. Forced nasogastric feeding then, is an absolute last resort. There is little doubt that this was the case in $\operatorname{Re} C M C$.

We can now return to the question of whether the MH Act is a more appropriate framework for the imposition of nasogastric feeding for anorexia than the PPPR Act. The

74 Jane Scott.

75 Above n 1, 343, 345-346.

76 AH Crisp in Anorexia Nervosa - Let Me Be, above n 42, 95; IL Mintz in "Psychoanalytic Description: The Clinical Picture of Anorexia Nervosa and Bulimia", above n 42, 214; MS Palazzoli in Self Starvation, above n 42, 99-103; S Gilbert in Pathology of Eating (Routledge \& Kegan Paul, London, 1986) 133.

77 AH Crisp Anorexia Nervosa - Let Me Be, above n 42, 97. 
main argument in favour of the $\mathrm{MH}$ Act is that it allows psychiatrists to get on with their job without having to resort to the court, especially where treatment is administered over an extended period. One writer argues that this is important because lawyers and judges do not understand what really happens with psychiatric patients, and attempts to promote their right to refuse treatment are "damaging to patients and destructive of treatment planning". 78

If this is simply an argument that psychiatrists know what is best for patients, the answer is that psychiatric patients have rights and they are entitled to have those rights upheld by a court.

If it is an argument about the inconvenience of obtaining a court order, this argument is not convincing in the case of nasogastric feeding for anorexia. The order in CMC was for feeding to be administered if necessary, over the period of a year. Since the treatment is an emergency one only, it is unlikely that a further order would be required after this period expired. If, due to the chronic nature of CMC's condition, a further order was required, it is submitted that it is not unduly onerous to require an application after a year. Psychiatrists are still responsible for deciding whether to make an application, and once the application is granted, whether and how often to impose feeding.

Given that avoidance of court proceedings is the only reason for using the $\mathrm{MH}$ Act, it is submitted that it is desirable to use the PPPR Act so that the patient has the protection of a court order. The imposition of medical treatment without consent is a serious undermining of the patient's personal rights. Mentally ill patients are inherently more vulnerable than others and perhaps more in need of the court's protection. It is desirable for a court to balance the various interests and considerations involved. The issue is not just a medical one, it is social and legal as well, which makes a court order appropriate.

Despite this, it is not clear from the judgment in Re CMC why CMC's case was dealt with in this way when other applications had been brought under the $\mathrm{MH}$ Act. It remains to be seen whether the PPPR Act will be used for these situations in future.

\section{THE DISCRETION}

According to section 9 of the PPPR Act, a finding of incompetence gives the court jurisdiction to make an order under that Act. The next step is for the court to exercise its discretion in deciding whether to grant the order. The objectives of the court in the exercise of its discretion are contained in section 8: to make the least restrictive intervention possible and to encourage the patient to develop her future capacity.

78 L McGarry and P Chodoff "The Ethics of Involuntary Hospitalisation" in Psychiatric Ethics (Oxford University Press, Oxford, 1981) 217. 
In $R e$ "Tony", ${ }^{79}$ the judge expressed the opinion that the section 8 objectives are relevant to the finding of jurisdiction as well as discretion. This was because: ${ }^{80}$

the issue of any shortfall in capacity or competence is not easily separated from consideration of the degree of intervention (if any) that may be required to make up for that shortfall ... the applicant may need to show not only an impairment in ... competence, but that the effect of that impairment is such that intervention is necessary.

The later case of $R v C^{81}$ rejected this approach, stating that the legislation clearly contemplated a two stage process, the first stage being a pure competence test.

Perhaps the differences between the two approaches would not amount to very much in practice. The approach in $R e$ "Tony" would involve consideration of social factors in determining the issue of competence. The writer has already stated that these other factors usually come in to a decision about competence, whether this is expressly admitted or not. Further, with orders for medical treatment, jurisdiction is always determined with reference to a particular treatment or course of action. In this way, it is difficult to separate the intervention issue from the competence issue.

In $\operatorname{Re} C M C$, Judge MacCormick treated the issues of jurisdiction and discretion separately. In exercising his discretion, the Judge stated that: ${ }^{82}$

Had CMC not expressed a wish to live, to recover fully and to lead a future life with her family and in particular her children, then in exercising the ultimate discretion it may perhaps have been appropriate to decline to make the order. But having regard to her stated wishes (other than those relating to treatment), I was satisfied that the proposed treatment was the least restrictive supplementary treatment that was available and that it was a form of treatment which hopefully might enable CMC to ultimately exercise and develop her own capacity to overcome her illness.

The Judge is obviously making reference here to the section 8 objectives. However, his comments go beyond these objectives in some respects. This is justified since the objectives are not strict rules, they are the primary objectives only. There still remains a discretion to take other factors into account. The following is an analysis of some of the other factors which Judge MacCormick appeared to consider in CMC's case.

79 (1990) 5 NZFLR 609.

80 Above n 79, 615.

[1992] NZFLR 162, 165-166.

82 Above n 1, 346. 


\section{A The Sanctity of Life, CMC's Wish to Live and CMC's Best Interests}

The Judge comments that if CMC had not expressed a wish to live, he may have declined to make the order for her medical treatment. It is necessary to consider the possible basis for such a decision.

It is recognised that the state has an interest in preserving life. This takes the form of an interest in preserving the life of the particular patient, and an interest in preserving the sanctity of all life. This abstract interest does not generally justify overriding an individual's right to refuse medical treatment. The patient has a much stronger personal interest in directing the course of her own life. ${ }^{83}$

Despite this respect for autonomy, courts are very reluctant to allow a patient to die and will go to great lengths to prevent this. When the result of a patient's refusal is likely to be death, the court can use the tool of competence to achieve the desired result. It was stated earlier that where a decision to refuse treatment will result in death, and treatment carries little risk, there is usually a finding that the patient is incompetent in some way.

In $\operatorname{Re} C M C$, there was no need to distort the concept of competence. CMC was clearly incompetent to make decisions regarding her medical treatment. This appears to justify the court's intervention to take measures to keep her alive. Does the court's intervention really depend on CMC's "wish to live"?

The emphasis on CMC's wishes can perhaps be attributed to a respect for autonomy. However, it could hardly be supposed that she was competent to make a decision as to whether or not she wanted to live. If she had expressed a wish to die, this decision would not have been respected because CMC was not competent to make it.

Perhaps the Judge is referring to the principles in section 8 . He states that, given her wish to live, the treatment is the least restrictive possible and one designed to encourage her to develop her future capacity. With respect to the principle of encouragement, perhaps if the treatment is to achieve this, CMC must have a desire to live. If CMC is not interested in recovery, nasogastric feeding can only be a measure to keep her alive. She can only develop her future capacity by overcoming her anorexia, and the initiative for this must come from her.

Is forced nasogastric feeding the "least restrictive intervention"? This is supposed to be judged according to "the degree of the subject person's incapacity". Judge MacCormick considers "least restrictive" with reference to CMC's wishes and her physical condition, not the degree of her incapacity. Nasogastric feeding appears to be the least restrictive alternative consistent with her living, because of her physical state. She wants to live, 
therefore nasogastric feeding is the least restrictive alternative consistent with her wishes. It is significant that Judge MacCormick does not mention the least restrictive intervention, but the least restrictive supplementary treatment. The point is simply that the least restrictive alternative must be judged against some goal or other, not just the degree of the person's incapacity. Here the goal was CMC's survival and recovery.

A similar approach was taken in the PPPR case of $R e W .{ }^{84}$ In that case the patient was 74 years old and was refusing food due to severe depression. Without the recommended treatment, he would die within a few days. Like CMC, he was incompetent to give consent but expressed a wish to live. Unlike $\mathrm{CMC}$, he was not refusing treatment. The judge accepted counsel's argument that one of W's personal rights protected by the PPPR Act, was his "personal right to live". Since $W$ had expressed a wish to live but was unable to change the course of events himself, there was a duty on the part of the court to promote his personal right to live. The recommended treatment was extremely risky, but was held to be the least restrictive alternative since it was the only treatment that had a chance of keeping W alive.

This analysis is confirmed by the judgment in In the Matter of $A_{,}^{85}$ a recent High Court decision under the PPPR Act. Counsel in that case argued that "least restrictive intervention" must be read as the least restrictive intervention possible to ensure that the person's welfare and best interests are cared for. This argument was effectively accepted by the court. This shows that the least restrictive intervention should be judged, according to the High Court, against the welfare and best interests of the patient.

In the Matter of $A$ holds that "welfare and best interests" is a hidden objective of the PPPR Act, in addition to those stated in section 8. According to the High Court, the purpose of the Act is clearly concerned with welfare and best interests, and to deny this is to play with words. It is likely that part of the real motivation for the decision in Re CMC was the Judge's feeling that nasogastric feeding was in CMC's best interests.

The danger with a best interests approach is that society will impose its judgment as to what is in the patient's best interests, at the expense of the patient's individual rights and autonomy. This is exactly what the PPPR Act aimed to avoid.

\section{B The Right to Die}

Consideration of the right or wish to live naturally leads to the question of the right to die. Judge MacCormick stated that he may not have granted the order had CMC not expressed a wish to live. What is the position if she had actually expressed a wish to die?

\footnotetext{
84 Above $\mathbf{n} 63$.

85 [1996] NZFLR 359.
} 
It is recognised that the state has an interest in the prevention of suicide. ${ }^{86}$ This is related to its interest in preserving life. It follows from this that the imposition of medical treatment without the patient's consent may be justified if the patient has done something in an apparent attempt to kill herself, and the treatment is to avert the consequences of that action. ${ }^{87}$ This is clearly the case if the suicide attempt is the result of mental illness or other temporary incapacity. In CMC's case, if she had expressed a wish to die, this would probably have been overridden because of her mental illness.

The difficulty in cases where the patient is competent is to distinguish a suicide attempt from an exercise of the right to refuse life-saving medical treatment. It may be that refusing treatment is simply a decision to let the illness run its natural course. The House of Lords has held that a decision to refuse treatment, even treatment prolonging life, is not suicide. ${ }^{88}$

In many cases of refusal of life-saving treatment, there is no issue of suicide because the patient has no specific intent to die. ${ }^{89}$ For example, a Jehovah's Witness who refuses a lifesaving blood transfusion does so out of faith. Her attitude is that whether she dies is God's decision. So in $\operatorname{Re} T$, Lord Donaldson described the case as not about the right to die, but the right to choose how to live. ${ }^{90}$ In Home Secretary $v$ Robb, ${ }^{91}$ Thorpe J held that a hunger striking prisoner was not committing suicide. He was simply refusing to be fed.

With anorexia, there is similarly no question of suicide because anorexic patients generally do not want to die. ${ }^{92}$ Indeed, Judge MacCormick held that CMC did not even believe or accept that she might die. The typical anorexic patient refuses to eat from fear of gaining weight, not in a deliberate attempt to kill herself. So the forced feeding of an anorexic patient cannot be justified on the ground of preventing suicide.

\section{CMC's Family}

As well as CMC's wish to live, Judge MacCormick noted her wish to live with her family and in particular her children. He stated that it may have been appropriate to decline to make the order had she not expressed this wish. It is obvious that the decision would affect her husband and children. Her husband was the applicant, who had brought

Above $\mathbf{n} 83$.

PDG Skegg Law, Ethics and Medicine (Clarendon Press, Oxford, 1988) 110.

Above $\mathbf{n} 68$.

Above $\mathbf{n} 83$.

Above $\mathbf{n} 31,786$.

Above n 28, 682 .

Jane Scott confirmed this. 
the application as a last resort, wanting to respect CMC's wishes but also wanting her to recover. It was also in the children's interests that their mother should recover and be able to care for them.

The difficulty is to find a legal basis on which the Judge can consider CMC's family situation when deciding whether to give her medical treatment without her consent. The PPPR Act does not expressly provide for the family's interests to be taken into account. However, orders under the PPPR Act usually do involve the patient's family in some way. It has been said that the main purpose of proceedings under the Act is often to permit families to act in ways that would otherwise be prevented by the incapacity of the patient. ${ }^{93}$

Judgments under the Act usually mention the family in some aspect. In $\operatorname{Re} W,{ }^{94}$ the judge mentioned W's family, stated that they had been consulted as much as possible, and that they supported the proposed treatment. The order for W's treatment was granted. In In the matter of $I M T,{ }^{95}$ the judge mentioned that the family were familiar with the proposed treatment and were keen for it to continue. The order for IMT's treatment was granted. In $\operatorname{Re} S,{ }^{96}$ the order for treatment was not granted since although $\mathrm{S}$ was incompetent, the proposed treatment was not the least restrictive possible. The judge stated that S's mother did not consent to the proposed treatment, and that she had taken him to a Maori herbalist.

The foregoing cases involved patients who were incompetent to consent, but in none of them was the patient actually refusing consent. It is a different matter to invoke the interests of a patient's family members to justify imposing medical treatment in the face of the patient's refusal.

Another possible basis for considering CMC's family is the State interest in protecting innocent third parties. In the United States, this interest has been recognised as one that can outweigh a competent individual's right to refuse treatment. ${ }^{97}$ On this view, CMC's children' can be seen as innocent third parties who will be harmed by her decision to refuse treatment.

In the United States, most of the cases on this subject involve the protection of unborn children when their mothers refuse to undergo Caesarean births for religious reasons. In

93 Above n 21, 51.

94 Above n 63, 576.

95 Above n 62, 613.

96 [1992] NZFLR 208.

97 Above $\mathrm{n} 83$. 
one case, ${ }^{98}$ the competent mother was ordered to undergo the Caesarean where the chances of survival through natural birth were very small, and the chances through Caesarean birth were good. The basis of these decisions is the entitlement of the unborn child to the law's protection. This was found to outweigh the mother's right to refuse treatment.

The only English case is $\operatorname{Re} S, 99$ a recent case in the Family Division. In $\operatorname{Re} S$, the competent mother refused a Caesarean for religious reasons and the operation was ordered because of the danger to mother and child from natural birth. The judgment was very short due to the urgency of the case. The reasons for the decision were not given in any detail, although the judge purported to rely on the American cases. ${ }^{100}$

The decision in $\operatorname{Re} S$ is highly controversial and has been criticised by commentators. ${ }^{101}$ One problem with the decision is that English courts have never recognised that any state interest can outweigh a competent person's right to refuse medical treatment. Another problem is that English law does not recognise an unborn child as having any legal existence. ${ }^{102}$

Despite criticism of $\operatorname{Re} S$, it may be that the idea of protection of innocent third parties is applied, but more conservatively than in the United States. In the 1995 case of Home Secretary $v$ Robb ${ }^{103}$ Thorpe J of the Family Division stated that: ${ }^{104}$

The consideration of protecting innocent third parties is one that is undoubtedly recognised in this jurisdiction, as is evidenced by the decision of Stephen Brown P in Re S....It seems to me that within this jurisdiction there is perhaps a stronger emphasis on the right of the individual's self-determination when balance comes to be struck between that right and any countervailing state interests.

Even if this interest is to be recognised, it would probably be limited to situations where the life of the innocent third party is in danger. CMC's children were not in any physical danger, they simply stood to lose someone who played a large part in their lives emotionally and financially. There is some American case law which suggests that a parent's

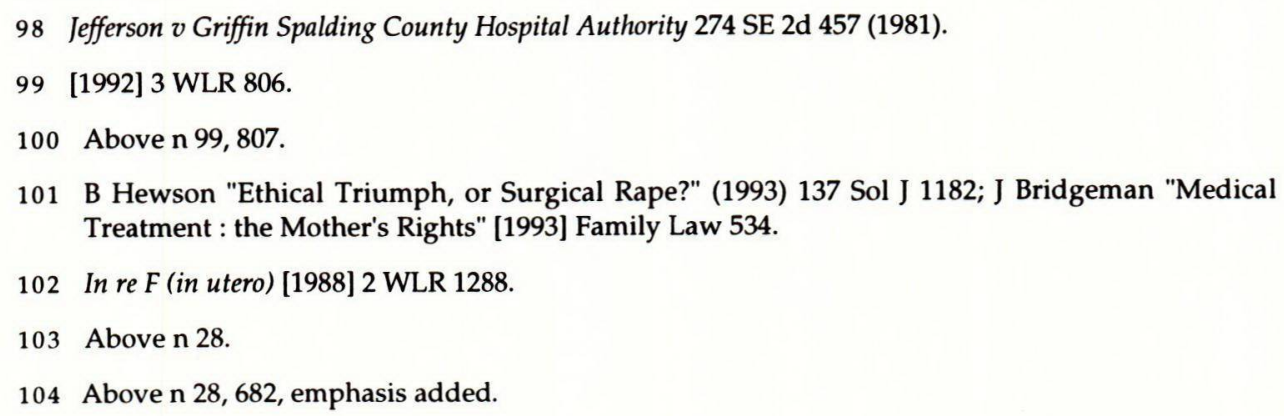


responsibility to her child may justify overriding her refusal of medical treatment. ${ }^{105}$ It is a huge step however, from the protection of the child's life to the protection of his or her general welfare.

It seems that the only legitimate basis for considering CMC's family is as part of CMC's wishes for her future life. In this way, the Judge is simply giving effect to her expressed wish to have a life with her children. This shows a respect for autonomy which is in line with the philosophy of the PPPR Act.

\section{CONCLUSION}

On the facts of $\operatorname{Re} C M C$, Judge MacCormick's decision is clearly the correct one. CMC would die without treatment, and her mental illness rendered her not competent to refuse that treatment. Anorexia nervosa affects a large number of women, although $\operatorname{Re} C M C$ was the first reported case to consider it. It may be that in these kind of cases, the court is in the end, forced to follow its conscience.

105 The Application of President and Directors of Georgetown College, Inc (1964) 331 F2d 1000. Kennedy and Grubb, above n 14, 358, suggest that this case was really a situation of lack of competence. 